\title{
A global vision
}

\author{
The Ecological Theatre and the \\ Evolutionary Play \\ by George Evelyn Hutchinson \\ Yale University Press, 1965
}

\begin{abstract}
Alison Jolly
"For the purposes of this seminar, let us define ecology as the study of the Universe." Evelyn Hutchinson's hooded blue eyes surveyed the graduate students assembled in Yale University's zoology department. We were products of the complacent 1950s and
\end{abstract} felt we were embarking on a voyage far from known shores, piloted by an ultraeccentric, ultra-English don.

Hutchinson told us about Arrhenius's notion that industrial carbon dioxide might lead to global warming. He mooted the idea that fertilizer affects the world's phosphate cycles, and wondered if it mattered that when the world's cows break wind, they emit methane. Apparently we lived in a 'biosphere', a concept derived from Vladimir Vernadsky's publications in French and Russian. Hutchinson zoomed from global biogeochemistry to animalcules so small that brownian motion rules their lives. He suggested that each living species occupies a multidimensional niche, perpetually jostled by the impact of other species, but mathematically tractable if you treat the niches' dimensions as finegrained scales of space and time. The web of ideas gleamed like spiderthreads stretched between stars. In 1965 Hutchinson published a slim book called The Ecological Theatre and the Evolutionary Play. He began by speculating whether life was probable on an Earthlike planet. He described the biosphere, the multidimensional niche, then lakes and ponds as microcosms. To help us understand these microcosms, Hutchinson embraced a range of knowledge from mud chemistry to thermal stratification, the relative growth rates of water-beetles, and the history of the surrounding agriculture. The details of this work he later covered in the four massive volumes of his Treatise of Limnology (Wiley, 1975-1993).

The Ecological Theatre and the Evolutionary Play instead danced onwards to the evolution of human intelligence, the phallic symbolism of Neapolitan coral babycharms, and the importance of randomness in human evolution and art. The book ended with an apparently trivial essay entitled "The Cream in the Gooseberry Fool". (It didn't stop to explain that a fool is an English recipe of fruit blended with dollops of heavy cream.) Here, Hutchinson dwelt on the Reverend Gilbert Raynor's passion for wing variation in the gooseberry moth, Abraxis grossulariata. Raynor's mothbreeding records finally became one small foundation of biochemical genetics. An onlooker described the 1907 sale of Raynor's collection as "gooseberry fool, mellowed...by some of that cream which regards these fine aberrations as matters of scientific interest and not, as so many say, postage stamps". in primates. (Hutchinson once sent a juvenile bushbaby hopping down the middle of the table in a department faculty meeting, convinced that even molecularly oriented colleagues would be enchanted by the creature. Unfortunately they weren't.) Is science the delight in bushbabies, pond-beetles and aberrant moth-wings, or the understanding that we need to guide our species through the current geological era, the Anthropocene? Hutchinson's larger vision was that the Universe is an interacting whole. James Lovelock has taken this much further with the concept of 'Gaia', which regulates Earth's systems so life can continue. Hutchinson was more cautious: he claimed only that in the macrocosm, as in the microcosm, everything is connected.

That vision now seems the basis of human survival. We have global warming. Global plagues. Global crises of water, land use and loss of biodiversity. Global, although certainly not free, trade. (I note that neither ring-tailed lemurs nor chimpanzees believe in free trade, and find it odd that many economists seem to.) John Maynard Smith and Eörs Szathmáry in their book The Major Transitions in Evolution (Freeman, 1995) explained the principles underlying the evolution of each of four great steps of biological synthesis: proto-life, eukaryotic cells, multicellular bodies, that are now known to affect the biosphere. widely acclaimed. His clutch of honorary doctorates culminated in the scarlet robes and Latin oration of the University of Cambridge, where his father had been master of Peterhouse College. But Hutchinson's colleagues at Yale were often exasperated, especially when he promoted heresies, such as Lynn Margulis's wild claim that eukaryote cells derive from symbiosis.

His students were chronically bemused. In our examinations he set us impossible questions: "Imagine an utterly isolated island in a constant environment. How big would it have to be to permit indefinitely ongoing evolution?" The students ricocheted off in all directions: towards limnology, or calculating species-area ratios on islands, or landscaping bits of the Amazon jungle to assess the minimum critical size of forest ecosystems, or analysing competition and symbiosis between rainforest trees, or studying maternal behaviour in goats and intelligence
Hutchinson's ecological theories were and the societies of mammals and insects. Arguably we are now approaching a fifth major transition of evolutionary integration: is humanity on the way to a species-wide society that recognizes its dependence on a species-wide environment? That couldn't evolve by darwinian natural selection, but it could develop by the purposeful use of human (and cyber) intelligence.

Our bounded life span and our eyesight that stops at the garden wall are in direct contrast with the need for a vision of the biosphere that extends over continents and centuries - and in the other direction, down to the single-celled rulers of biogeochemistry. One of Hutchinson's impossible examination questions was: "Discuss the effect of man's size on his view of the Universe." At the time, no student dared tackle an answer. All of us, though, still wish we had.

Alison Jolly is in the Department of Biology and Environmental Sciences, University of Sussex, Brighton BN1 9QG, UK. 